Skidmore College

Creative Matter

Sociology Senior Seminar Papers

Sociology

$5-2019$

\title{
A Division III Study: Does Being a Collegiate Athlete Cause Lower GPAs, While Also Causing Negative Treatment in the Classroom by Other Students?
}

Gabriela Tanaka

Skidmore College, gtanaka@skidmore.edu

Follow this and additional works at: https://creativematter.skidmore.edu/socio_stu_stu_schol

Part of the Demography, Population, and Ecology Commons

\section{Recommended Citation}

Tanaka, Gabriela, "A Division III Study: Does Being a Collegiate Athlete Cause Lower GPAs, While Also Causing Negative Treatment in the Classroom by Other Students?" (2019). Sociology Senior Seminar Papers. 31.

https://creativematter.skidmore.edu/socio_stu_stu_schol/31

This Thesis is brought to you for free and open access by the Sociology at Creative Matter. It has been accepted for inclusion in Sociology Senior Seminar Papers by an authorized administrator of Creative Matter. For more information, please contact dseiler@skidmore.edu. 


\title{
Running Head = ACADEMIC SUCCESS, ATHLETE VERSUS NON-ATHLETE
}

A Division III Study: Does Being a Collegiate Athlete Cause Lower GPAs, While Also Causing Negative Treatment in the Classroom by Other Students?*

\author{
Gabriela Tanaka \\ Skidmore College
}

Word Count $=6,287$

*Please direct all correspondence to Gabriela Tanaka, 815 N Broadway, Mailbox 2391, Saratoga Springs, NY 12866. Email: gtanaka@skidmore.edu 
A Division III Study: Does Being a Collegiate Athlete Cause Lower GPAs, While Also Causing Negative Treatment in the Classroom by Other Students?

There are many debates about the relationship between athletics and academic performance in the American liberal arts system. This study proposes that there is a negative treatment of athletes by other students in the classroom. It also reveals that athletes have lower GPAs than non-athletes. Using a data set collected at Skidmore College in 2006, these questions are analyzed. This study investigates the degree to which athletes perform compared to nonathletes and their treatment by other students. The sample had 361 valid respondents of whom 50 percent were athletes, and 66 percent of the sample were women. The results demonstrate that athletes, on the whole, have lower GPAs than non-athletes. It also shows that women have higher GPAs than men, which was expected. Based on the findings at Skidmore College in 2006, students did not feel that they were treated poorly by other students just because they were athletes. The data confirms the first hypothesis which stated that on average athletes will have lower GPAs than non-athletes. However, the second hypothesis that athletes were more likely to agree that athletes are treated more poorly than non-athletes was not supported by the data. 
Attending college has become more of a custom in the recent years. There are many options for college such as large state schools and also small liberal arts colleges. The importance of sports in college life varies significantly across different types of institutions. Large state schools value sports in such a way that academics can sometimes get pushed to the wayside. Small liberal art schools value first and foremost the academic standing and character of their students. DI schools value the athlete, while DII and DIII schools value academics first and athletics second. DI schools have been known to accept students for their athletic ability alone, while providing them with numerous tutors, tactics, and leniency towards their academics. DIII schools pride themselves on the student athlete. This means that athletics come second to academics and that students must be academically competent on their own. Athletics are still competitive at DIII schools but the athletic culture is much less strong. There is much speculation on whether colleges accept students based on GPA and SAT performance alone, or if other factors lead to the decision such as sports ability.

At Skidmore College, a DIII school, the recruiting process also factors in the students academic level and success in high school, so students have to be academically competent to get accepted. Skidmore being a predominantly female campus also adds gender as a factor. Does having more women on a campus change the attitudes on campus, and in sport? Are athletes different to non-athletes in the classroom when it comes to treatment and performance?

I seek to find out whether athletes and non-athletes have different college experiences academically at Skidmore College. I have compared Skidmore athletes against non-athletes and their academic successes by measuring their GPAs. I want to discover whether the academic culture at Skidmore views athletes negatively and will therefore exclude them from feeling welcome in an academic setting. I wish to understand whether non-athlete students view athletes 
in a negative light in the classroom, and if so does that negativity affect how athletes feel about themselves academically. If athletes are feeling discriminated against in the classroom, are they at risk for stereotype threat that may cause them to perform less well academically? It is important to study academic culture at Skidmore to determine if there are any fundamental issues with how Skidmore students treat athletes in an academic setting.

Another important factor is gender. Are female athletes viewed in a different way to male athletes? This study uses several theories, including Social interactionism (Rubin and Moses 2017), to examine gender differences in the classroom (Watson 1987). In relation to social interactionism, role conflict theory explained differences in student identities with potentials leading stereotype threat (Beron and Piquero 2016).

I used a dataset called the 2006 NCAA Growth, Opportunities, Aspirations, Learning of Students in College (Goals) survey. This survey was answered by Skidmore College students. With it I investigated the relationship between student athletes and non-athletes in relation to academic achievement. The data set was provided by Skidmore College. I hypothesize that on average athletes will have lower GPAs than non-athletes. The second hypothesis is that athletes are more likely to agree that non-athletes treat athletes poorly because they are athletes.

\section{LITERATURE REVIEW}

A long-debated question in the literature is whether collegiate athletes perform well in the classroom in comparison to their peers. The NCAA has raised many questions as to whether this is the case. While most research focuses on D I athletes, there is some information on D III athletes. There is also much deliberation over previous studies and literature due to conflicting results with certain studies stating that athletes perform better (Purdy, Eitzen, and Hufnagel 
1982; Rehberg and Shafer 1968) and others stating that athletes do worse academically (Kiger and Lorentzen 1986; Maloney and McCormick 1993; Eitzen 1987). While some believe that the hard work ethic instilled in athletes rolls over to academics (Rehberg and Shafer 1968), others believe that athletes do not prioritize school (Alder and Alder 1985).

\section{I Versus D III and GPA Expectations}

Since the NCAA has rules on GPAs and overall performance to be eligible to play the sport itself, the line can become blurred when the school itself is invested financially in its sports and athletes. This is best explained by Rubin and Moses (2017) when they argue that in essence Neoliberalism would suggest that everything has a financial reason for being. As college is an institution, it follows the template of having financial motives. The college needs enough money to continue and pay its professors, while providing facilities and dining services to ensure students happiness and high education and comfort. This is true for both D I schools and D III schools.

There is also a financial incentive to strategically enroll students to ensure that enough students will attend college paying full tuition. This fact is important when it comes to athletes because if a school is D I it seems that the school would hope to make money off of the teams, therefore recruiting is important when considering enrolment (Rubin and Moses 2017). D I schools try to make money off of teams by ticketing games. The students and general public must pay to gain entry to the stadiums.

According to Stanely Eitzen (1987), “critics of intercollegiate sport argue that winning, which is highly correlated with revenues, has corrupted higher education. Most specifically, at some schools the athletic performance of athletes is more important than their academic achievement" (Eitzen 1987:15). Scandals in D I schools have highlighted this problem such as 


\section{ACADEMIC SUCCESS, ATHLETE VERSUS NON-ATHLETE}

falsifying transcripts and adding fake classes to the curriculum, all just to ensure that the athlete can remain eligible to play the games (Purdy et al. 1982). This conflict is however more of an issue in D I schools as opposed to D III schools. D III schools do not make money off of their sports teams, and value the student before the athlete.

While D I schools allow athletes to have low GPAs and still be eligible to play, D III schools have different standards. In D III schools, athletes must have good academic standing which is determined by each college (Beron and Piquero 2016). "There are three standard predictors of college performance - the combined score on the Scholastic Aptitude Test (SAT), the American College Test (ACT) composite score, and high school grade point average," (Eitzen 1987:15). Some research suggests that athletes are on the whole less prepared for college, scoring lower on their SATs and ACTs. They also seem to have lower GPAs in general from high school (Robst and Keil 2000; Kiger and Lorentzen 1986; Maloney and McCormick 1993; Sellers 1992). This suggests that DI schools overlook all of the predictors and accept students based on athletic talent. However once at college certain research mentions that athletes actually take more credits and more difficult course loads per academic year (Robst and Keil 2000). This tends to contradict the theory that athletes are less prepared for college. Other research states that athletes also seem to take a larger breadth of courses in different departments in comparison to non-athletes (Brede and Camp 1987).

Athlete Versus Non-Athlete and GPA

At the start of college, evidence suggests that athletes arrive with high hopes to be both academically and athletically successful. However, it seems once they come in contact with the team, individuality is lost and the individual meshes with the team. It seems that once on the team players start achieving similar lower GPAs and start to feel academically detached from the 
other students who are not athletes (Adler and Adler 1985; Cokley et al. 2015; Cooper, Davis, and Dougherty 2017). The hours and amount of practice athletes are required to participate in foster the disengagement towards academics (Eitzen 1987). Male teams are often found to be clustering in majors. This means that twenty-five percent of the team is in the same major, therefore many of them are in the same classes (Eitzen 1987). On the other hand, some research shows that athletes display greater levels of academic engagement (Clopton 2012). This highlights all the different points of view on this topic.

Whether an individual has an academic identity versus athletic identity plays a large role into how academically successful they will be (Beron and Piquero 2016; Harrison et al. 2009). It is clear from all prior research that identity is exceedingly important on how successful a student may be in an academic setting (Maloney and McCormick 1993; Harrison et al. 2009; Beron and Piquero 2016). If an individual's identity is predominantly one of an athlete, the individual is more likely to do poorly in comparison to and individual whose identity is dominated by academic potential and drive.

“College athletes tend to underperform, as measured by GPA,” (Eitzen 1987:20; Maloney and McCormick 1993). If an individual is an athlete, they are more likely to do poorly based on stereotype threat (Adler and Adler 1985; Harrison et al 2009; Beron and Piquero 2016). In a classroom setting if an individual is reminded that they are an athlete they will automatically confirm this bias (Harrison et al. 2009). Students who are athletes are more at risk for stereotype threat in comparison to students who are non-athletes.

Gender and GPA and Athlete Versus Non-Athlete

Gender plays a role in academics as females generally perform better than males academically (Quadlin 2018; Cokley et al. 2015; Vilhauer and Rosonke 1991; Dilley-Knoles, 
Burnett, and Peak 2010; Beron and Piquero 2016; Sack 1987). They get better grades and have a higher GPA (Quadlin 2018). It seems that female students perform similarly to other female students regardless of whether or not they are an athlete (Eitzen 1987; Purdy et al. 1982; Cokley et al. 2015; Quadlin 2018; Vilhauser 1991). One argument for why males do less well is that “...Male athletes are less well prepared for college than male non-athletes. Female athletes, on the other hand, are similar to other females in the student body." (Eitzen 1987:15)

Women have been known to have more academic success in comparison to males (Harrison et al. 2009). In general performance suffers when athletic identities clash with academic identities (Harrison et al. 2009). The "maintenance of identities is not a simple task for women" (Watson 1987:444). The athlete is afraid to confirm negative stigmatized identity and could end up doing just that (Harrison et al. 2009). This is stereotype threat.

Women seem to do better than males academically. This is due to men having a higher athletic identity, and women seem to have higher academic identity (Beron and Piquero 2016). Males on the other hand consistently score lower than women (Vilhauser 1991). The difference is particularly clear with male athletes when compared to male non-athletes (Vilhauser 1991). The "Athletic subculture the women are a part of, as well as their classroom and academic experiences, may to some degree influence or reinforce their educational optimism," (Meyer 1990:44). Not to mention that women in D III and DI schools have a lower likelihood of going pro in comparison to men, thus women have to focus on academics to ensure a fruitful future (Harrison et al. 2009).

Another reason that women do better than men academically is the fact that female athletes are much less likely to think of themselves as "Jocks" which carries a negative academic connotation while male athletes are at high risk of being perceived that way (Clopton 2012). The 
concept of a "dumb jock" is a highly gendered stereotype and also a very pervasive concept (Watson 1987; Brede and Camp 1987). This stereotype does not apply to women the way it does to men due to the fact that women are not expected to outwardly show that they are athletes (Watson 1987). In short being a women and being an athlete are still seen as separate from each other and as Desertrain and Weiss (1988) state the two roles are conflicting. This gender divide causing women not to be seen as dumb jocks but male athletes to be categorized as such would explain why only males believe that overall athletes are not as intelligent as non athlete students as a result of the female and athlete role being in conflict (Sailes 1993). While women are not outwardly seen as athletes males who are athletes are in full view and cannot escape the stereotype.

\section{Athlete Social Life and Treatment}

There is little research on whether or not an athlete feels singled out in the classroom. The main focus is how well athletes fare against non athletes. However, whether or not an athlete feels welcome in the classroom is just as important. It seems that athletes are asked to spend so much time together that they develop "collectivist" ideals (Eitzen 1987). Teams often develop group think, whether this become apparent with many team members choosing the same major or how intense of an emphasis a team puts on academic success (Eitzen 1987; Rubin and Moses 2017; Cooper et al. 2017). While spending so much time with their athlete peers, athletes isolate themselves from non-athletes. In the classroom there is a preference towards sitting together and in some ways alienating their peers (Eitzen 1987; Rubin and Moses 2017; Cooper et al. 2017). Athletes therefore may not be single out on the classroom noticeably because they have their athletic peers and teammates support. Though college athletes so not perform as well in the classroom as their peers (Maloney and McCormick 1993), and the pressure to win athletically 
can hinder the students' ability to perform and be invested in the classroom (Diley-Knoles et al. 2010), athletes' academic goals are influenced by their teammates (Adler and Adler 1985), therefore any negative treatment would come directly from them.

While there are differences in D I schools when compared to D III schools, many of the trends seem to follow such as, women performing better academically than men, women athletes having comparable GPAs to female non athletes, males being stereotyped as "dumb jocks" and athletes isolating themselves from their non athlete peers. It is important to understand why this is the case specifically when looking at Skidmore College and its trends. Does Skidmore College follow suit of D I schools or does being a D III school have an impact on the results?

\section{THEORETICAL FRAMEWORK}

\section{Role Conflict}

This concept is one that people encounter regularly and it has an influence on their life and how they act or react. For the purposes of this paper, role conflict relates to the athletic identity versus the academic identity. These identities strongly impact the way that students act and perform in class. While females have an easier time separating the fact that they are an athlete and their academic career, males struggle more deeply with this. Males have a stronger sense of athletic identity. Females on the other hand perform higher in the classroom due to the fact that while in the classroom their sense of identity is academic. If, however a female is reminded that they are an athlete in an academic setting these two identities come into conflict. This process makes it more likely for women to fall into the self-fulfilling prophecy of stereotype threat. This would then cause women to perform less well compared to their non athletic peers (Beron and Piquero 2016; Harrison et al. 2009). 
ACADEMIC SUCCESS, ATHLETE VERSUS NON-ATHLETE

\section{Symbolic Interactionism}

Everyone goes through the process of being socialized but the process is different for each person. Symbols are learned that have shared meaning or values. One key point is that "the experience of the self rests on the capacity to see ourselves from the vantage point of others."(Rubin and Moses 2017) Gender roles also are learned during this period and also come into affect in academics. The dumb jock stereotype is socialized into us at a young age. This stereotype that is so deeply ingrained into the population can lead to stereotype threat. While women are also athletes they are "athletic women" and not "women athletes." Therefore, the concept itself is highly gendered (Watson 1987).

\section{RESEARCH METHODS}

\section{Dataset}

I have used a dataset from 2006 that was conducted at Skidmore College. The dataset is called the 2006 NCAA Growth, Opportunities, Aspirations, Learning of Students in College (Goals) survey. This survey was answered by Skidmore College Students. The questions asked ranged from academics, extracurriculars and other commitments, as well as social life and health. There were two versions of the survey, one targeted towards athletes and the other targeted toward non-athletes. The original purpose when the test was administered was to see differences between athletes and non-athletes. As a result, there are more athletes in the sample compared to non-athletes. The response rate was 14 percent for non athletes and 73 percent for athletes. Skidmore College's population in 2006 had 15 percent athletes and 85 percent non-athletes, however the sample had 48 percent athletes and 52 percent non athletes. 
In total there were 564 respondents to the survey. Skidmore College had 2462 students in 2006. Therefore, the overall response rate was 23 percent. While there were 564 respondents, missing data forced the sample size to be reduced to 361 . To delete the data listwise deletion was implemented. The unit of analysis is the individual. There were significantly more female respondents than male respondents. Which is an accurate reflection of Skidmore's student population. For further information on the 2006 NCAA Growth, Opportunities, Aspirations, Learning of Students in College (Goals) survey, contact Catherine Berheide cberheid@skidmore.edu or go to the NCAA website at www.ncaa.org.

\section{Variables}

My independent variable is nominal and it is whether you are an athlete or non-athlete currently. It is a dummy variable that is measured, athlete $=1$ and non-athlete $=0$. My controls are gender, time studying, and hours spent on extra curricular activities. Gender is dummied so that female $=1$ and male $=0$. Time studying refers to how much time on average a respondent spent studying. When asked "While school was in session during the past semester, picture the weekday (Monday to Friday) that felt like your 'typical' day on campus. On that day, how many hours did you spend on this activity?" The respondent had the option to answer from 0 to $8+$ hours. For hours spent on extracurricular activities the respondent was asked "If you could, would you prefer to spend more or less time in this area while in college?" Then the respondent could answer "much more time," "little more time," "ok with current time," "little less time," "much less time." 1 means that the respondent would like to spend much more time on extracurriculars. 5 means that the respondent would rather spend much less time on extracurriculars. 
One of the dependent variables is GPA which has been recoded into the midpoint of the GPA categorical values. I use a variable that asks whether students treat athletes poorly because

they are athletes. The question is "I feel that some students treat athletes on this campus poorly because they are athletes?" The question is coded so that the lowest number (1) corresponds to strongly disagree and the highest number (6) corresponds with strongly agree. The other dependent variable is whether or not students treat athletes poorly. The prompt was "I feel that some students treat athletes on this campus poorly because they are athletes." Respondents could answer from strongly disagree with the statement which was (1), disagree with statement (2), somewhat disagree with statement (3), somewhat agree (4), agree (5), and strongly agree (6).

\section{FINDINGS}

\section{Univariate Results}

Table 1 shows the means, medians, and standard deviations of all the variables, beginning with the independent variable, and followed by the dependent and control variables.

Table 1 Here

My first variable is whether the respondent is a current athlete or not. This variable is a dummy variable. This variable has a mean of .51 which means that about half of the respondents are current athletes. The next variable is GPA which was recoded to have all midpoints of each grade. The mean GPA in the group of respondents was 3.35 which means that the average GPA consisted of respondents receiving an average grade of a $\mathrm{B}+$. There are more women than men in this sample. Poor athlete treatment was measured 1 to 6.1 means strongly disagree and 6 means strongly agree that students treat athletes poorly. The mean is 3 which means that more respondents somewhat disagree that students treat athletes poorly. On the whole respondents feel 
good about the amount of time they spend on their extracurriculars as the mean for this variable is 4 , which states that respondents are ok with current time spent on extracurriculars. This variable is measured 1 to 5 . The variable that measures how much a respondent studies on an average weekday is 3.39 hours.

Figure 1 shows whether respondents in this sample are athletes or not. It shows that about half of the respondents are athletes while the others are non-athletes. 50.7 percent of respondents are athletes and 49.3 percent of respondents are non-athletes.

Figure 1 Here

Figure 2 displays the breakdown of GPA. This figure shows the amount of respondents percentage wise and their GPAs. 33.2 percent of respondents have an average of a $\mathrm{B}+$.

Figure 2 Here

Figure 3 represents whether students agree that students treat athletes poorly. 32.1 percent of respondents disagree that students treat athletes poorly, while 20.8 somewhat agree that students treat athletes poorly.

Figure 3 Here

Figure 4 shows whether the respondents are male or female. The sample has more females than males. There sample shows that 34.1 percent of the sample are males. 65.9 percent of the respondents are female. This is not surprising due to the fact that Skidmore has more female students than male students.

Figure 4 Here

Figure 5 represents the amount of hours a respondent spends studying on an average weekday. 28.8 percent of respondents spend an average of three hours studying on an average weekday. 
Figure 5 Here

Figure 6 displays how much time respondents spend their extracurricular time. 54.3 percent of respondents wish they could spend a little more time with their extracurriculars. 32.1 percent of respondents are pleased with the amount of time they currently spend on their extracurriculars.

Figure 6 Here

\section{Bivariate Findings}

The data in Table 2 does not produce any correlations that are greater than .70, therefore there is no multicolinearity problem. There is a weak to moderate positive relationship between women and GPA. This means that on average women have higher GPAs than males. There is no relationship between time extracurricular and GPA. There is a very weak positive relationship between GPA and average study time weekday. This means that people who study more have higher GPAs. There is a weak negative relationship between being an athlete and GPA. Therefore, athletes have lower GPAs than non-athletes. There is a very weak negative relationship between students that agree that students treat athletes poorly and GPA. This is to say that as GPA increases you are less likely to agree that students treat athletes poorly.

A very weak relationship is found between time extracurricular and women. This states that women spend more time on extracurricular activities compared to males. No relationship is found between average study time weekday and women. This is also true for average study time weekday and time extracurricular. 


\section{ACADEMIC SUCCESS, ATHLETE VERSUS NON-ATHLETE}

There is a negative very weak relationship between being a women and being an athlete. This means that women are less likely to be athletes. There are no relationships between being an athlete and time extracurricular, and being an athlete and average study time weekday. However, there is a negative weak relationship between woman and students agree that students athletes poorly. This means that women are less likely to agree that students treat athletes poorly. A negative very weak relationship is found between students agree that students treat athletes poorly and time extracurricular. Therefore, students are less likely to agree that students treat athletes poorly if they participate in extracurricular activities. There is no relationship between students agree that students treat athletes poorly and average study time weekday. There is also no relationship between students agree that students treat athletes poorly and athlete.

Table 2 Here

\section{Multivariate Regression Analysis}

Table 3 shows the regression analysis for both dependent variables, GPA and student agrees students treat athletes poorly. The $R^{2}$ value for GPA is .134 which means that 13.4 percent of the variability in GPA can be explained by all variables: being an athlete, gender, average study time on a weekday, and whether the student would prefer to spend more time on extracurricular activities. The regression is statistically significant at the .05 level because the $\mathrm{F}$ is large at 13.737. Both women and athletes are significant predictors of GPA. Athletic status has a negative statistically significant relationship with GPA. Using only Betas, which are standardized coefficients from the regression analysis that allow the numbers to be compared to each other, being a woman has the largest effect on GPA of all factors. The $R^{2}$ of the second regression analysis is .057 which means that 5.7 percent of the variability in whether students agree that students treat athletes poorly because they are athletes can be explained by all factors. 
The regression is statistically significant due to the F being 5.341. However, in this regression only gender has a statistically significant negative relationship with whether students agree that students treat athletes poorly because they are athletes. Gender has the biggest effect on GPA. Being a woman results in higher GPA and women are less likely to agree that students agree that athletes are treated poorly.

\section{Table 3 Here}

\section{DISCUSSION}

Using the results from both the correlation table and the regression analysis, women on average at Skidmore College have higher GPAs than males. Being an athlete on the whole results in lower GPAs than non-athletes. The correlation table results show that women tend to obtain higher GPAs than males. Women are also less likely to believe that athletes are treated poorly because they are athletes. This is due to the fact that women get higher GPAs and do not have the same conflict that men do when it comes to being an athlete. The correlation table shows that athletes are more likely to be male at Skidmore College. Since there are less women athletes and women tend to get higher GPAs, it makes sense that women do not feel discriminated against in the classroom due to the fact that they are an athlete. The regression table shows that women have higher GPAs than men which is supported by Quadlin (2018), Cokley et al. (2015) and Eitzen (1987). It also shows gender has the greatest effect on GPA of all the factors.

The results support the hypothesis that women have higher GPAs than men (Quadlin 2018; Cokley et al. 2015; Vilhauer and Rosonke 1991; Dilley-Knoles, Burnett, and Peak 2010; Beron and Piquero 2016; Sack 1987). The data found shows athletes have lower GPAs that nonathletes which is consistent with Adler and Adler (1985) as well as Cokley et al. (2015). It must 
be taken into account that more athletes are male in the sample and that male athletes fare much lower in terms of GPA in comparison to non-athletes (Vilhauser 1991). Since women score higher academically, they are less at risk to be called a "dumb jock" and therefore also less likely to fulfil that stereotype (Clopton 2012; Watson 1987; Brede and Camp 1987). This in particular ties into symbolic interactionism. The "dumb jock" stereotype is highly gendered meaning that women are more detached from it (Watson 1987). Because women are less likely to fulfil this stereotype, they are also less likely to believe that athletes are treated poorly by other students.

Based on the data found at Skidmore College, neoliberalism was not relevant in the way it would be at any DI school (Rubin and Moses 2017). Neoliberalism will always have an effect on every college but not with these results. Since Skidmore College is a DIII school; the focus of the athletics program is not revenue based. Role conflict theory and identity play a large role in understanding the results. The highly gendered stereotype of the "dumb jock" does not apply to women therefore they suffer less often with role conflict theory (Beron and Piquero 2016; Harrison et al. 2009). Women have higher GPAs than men which supports that their academic identity is dominant over their athletic identity in the classroom (Beron and Piquero 2016; Harrison et al. 2009). These results show that Skidmore College is not exempt from gendered stereotypes which effect students inside the classroom and their academic achievement.

The literature states that athletes isolate themselves from the rest of their college peers who are non-athletes (Eitzen 1987; Rubin and Moses 2017; Cooper et al. 2017). They then associate with each other meaning that they are not treated poorly by other students because they have limited or close to no interactions with them (Eitzen 1987; Rubin and Moses 2017; Cooper et al. 2017). With this in mind, the fact that athletes are not perceived to be treated poorly must be due to the two groups, athletes and non-athletes, being kept separate. 
ACADEMIC SUCCESS, ATHLETE VERSUS NON-ATHLETE

\section{CONCLUSION}

The purpose of the study was to determine whether athletes had lower GPAs than nonathletes and whether athletes were treated poorly at Skidmore College. The 2006 NCAA Growth, Opportunities, Aspirations, Learning of Students in College (Goals) survey was used to analyze whether or not athletes had different college experiences academically. The sample size was 361 . The results show that athletes have lower GPAs than non-athletes and that women have higher GPAs than men. However, at Skidmore College women were less likely than men to agree that athletes were treated poorly because they were athletes. The data confirms the first hypothesis that on average athletes will have lower GPAs that non-athletes. The second hypothesis that athletes are more likely to agree that non-athletes discriminate against athletes was not supported by the results. The results support symbolic interactionism theory and role conflict theory.

\section{Limitations}

There were a few limitations to this study. One of these limitations was the sample size. Due to missing data and having to delete cases, there were only 361 valid cases. The survey had 564 respondents and only 361 were analyzed. Of course it was not possible to control for all variables that could have had an impact.

Future research should continue to focus more on DIII schools to find the patterns in those schools. The current research does not accurately represent all DIII schools. In the future research should determine whether athletes take the same majors as non-athletes or if they are more likely to do so. There should be more research into the effects of race, income, and potentially where a student is from to see if these variables influence the results.

The importance of this study is to understand if athletes at a liberal arts school like Skidmore College follow the same trends as athletes at a DIII school. Skidmore follows trends 
like other DI schools, such as women having higher GPAs than men. On the plus side, the findings suggest that non-athletic students at Skidmore College do not discriminate against athletes. Skidmore College values education and academic success therefore the fact alone that Skidmore is a DIII school and not a DI school shows a significant difference. More research should be done at DIII schools due to their emphasis on prioritizing the student over the athlete. Students at DIII schools produce more rounded students who are ready for the world that lies outside of the college walls. 
ACADEMIC SUCCESS, ATHLETE VERSUS NON-ATHLETE

\section{REFERENCES}

Adler, Peter, and Patricia A. Adler. 1985. "From Idealism to Pragmatic Detachment: The Academic Performance of College Athletes." Sociology of Education 58(4):241-250.

Beron, Kurt J., and Alex R. Piquero. 2016. "Studying the Determinants of Student-Athlete Grade Point Average: The Roles of Identity, Context, and Academic Interests." Social Science Quarterly 97(2):142-160.

Brede, Richard M., and Henry J. Camp. 1987. "The Education of College StudentAthletes." Sociology of Sport Journal 4(3):245-257.

Clopton, Aaron W. 2012. "Social Capital, Gender, and the Student Athlete." Group Dynamics 16(4):272-288.

Cokley, Kevin, Germine Awad, Leann Smith, Stacey Jackson, Olufunke Awosogba, Ashley Hurst, Steven Stone, Lauren Blondeau and Davia Roberts. 2015. "The Roles of Gender Stigma Consciousness, Impostor Phenomenon and Academic Self-Concept in the Academic Outcomes of Women and Men." Sex Roles 73(9-10):414-426.

Cooper, Joseph N., Davis, Tiffany J. and Dougherty, Shaun. 2017. "Not so Black and White: A Multi-Divisional Exploratory Analysis of Male Student-Athletes' Experiences at National Collegiate Athletic Association (NCAA) Institutions.” Sociology of Sport Journal 34(1): 5978.

Desertrain, Gloria Solomon., and Weiss, Maureen R. 1988. "Being female and athletic: A cause for conflict?" Sex Roles. 18(9-10):567-582. 
Dilley-Knoles, Jennifer., Jeffery S Burnett, and Kayla W Peak. 2010. “Making the grade: Academic Success in Today's Athlete." The Sport Journal 13(1):1-9.

Eitzen, Stanley D. 1987. "The Educational Experiences of Intercollegiate Student -Athletes." Journal of Sport \& Social Issues 11(1):15-30.

Harrison, Keith C., Jeff Stone, Jenessa Shapiro, Sharon Yee, Jean A. Boyd and Vashti Rullan. 2009. "The Role of Gender Identities and Stereotype Salience with the Academic Performance of Male and Female College Athletes." Journal of Sport and Social Issues 33(1):78-96.

Kiger, Gary and Lorentzen, Deana. 1986. "The Relative Effects of Gender, Race, and Sport on University Academic Performance." Sociology of Sport Journal (3):160-167.

Maloney, Michael T., and Robert E. McCormick. 1993. "An Examination of the Role that Intercollegiate Athletic Participation Plays in Academic Achievement: Athletes' Feats in the Classroom." The Journal of Human Resources 28(3):555-570.

Meyer, Barbara B. 1990. "From Idealism to Actualization: The Academic Performance of Female Collegiate Athletes." Sociology of Sport Journal 7(1):44-57.

NCAA Growth, Opportunities, Aspirations, Learning of Students in College (Goals) survey. 2006.

Purdy, Dean A., Stanely Eitzen, and Rick Hufnagel. 1982. "Are Athletes Also Students? The Educational Attainment of College Athletes." Social Problems 29(4):439-448.

Quadlin, Natasha. 2018. "The Mark of a Woman's Record: Gender and Academic Performance in Hiring." American Sociological Review 83(2):331-360. 
Rehberg, Richard A., and Schafer, Walter E. 1968. "Participation in Interscholastic Athletics and College Expectations.” American Journal of Sociology 73(6):732-740.

Robst, John, and Jack Keil. 2000. "The Relationship between Athletic Participation and Academic Performance: Evidence from NCAA Division III." Applied Economics 32(5):547558.

Rubin, Lisa M., and Ron A. Moses. 2017. "Athletic Subculture within Student-Athlete Academic Centers." Sociology of Sport Journal 34(4):317-328.

Sack, Allen L. 1987. "College Sport and the Student—athlete." Journal of Sport and Social Issues 11(1-2):31-48.

Sailes, Garry A. 1993. “An Investigation of Campus Stereotypes: The Myth of Black Athletic Superiority and the Dumb Jock Stereotype.” Sociology of Sport Journal 10(1): 88-97.

Sellers, Robert M. 1992. "Racial Differences in the Predictors for Academic Achievement of Student-Athletes in Division I Revenue Producing Sports." Sociology of Sport Journal 9(1):48-59.

Videon, Tami M. 2002. "Who Plays and Who Benefits: Gender, Interscholastic Athletics, and Academic Outcomes." Sociological Perspectives 45(4):415-444.

Vilhauer, Dave, and Rosonke, Jermone. 1991. “Assessing The Myth: A Study of Eligible Ahtletes' Grade Point Averages.” The Great Plains Sociologist 4 (1): 51-61.

Watson, Tracey. 1987. "Women Athletes and Athletic Women: The Dilemmas and Contradictions of Managing Incongruent Identities.” Sociological Inquiry 57(4):431-446. 
ACADEMIC SUCCESS, ATHLETE VERSUS NON-ATHLETE

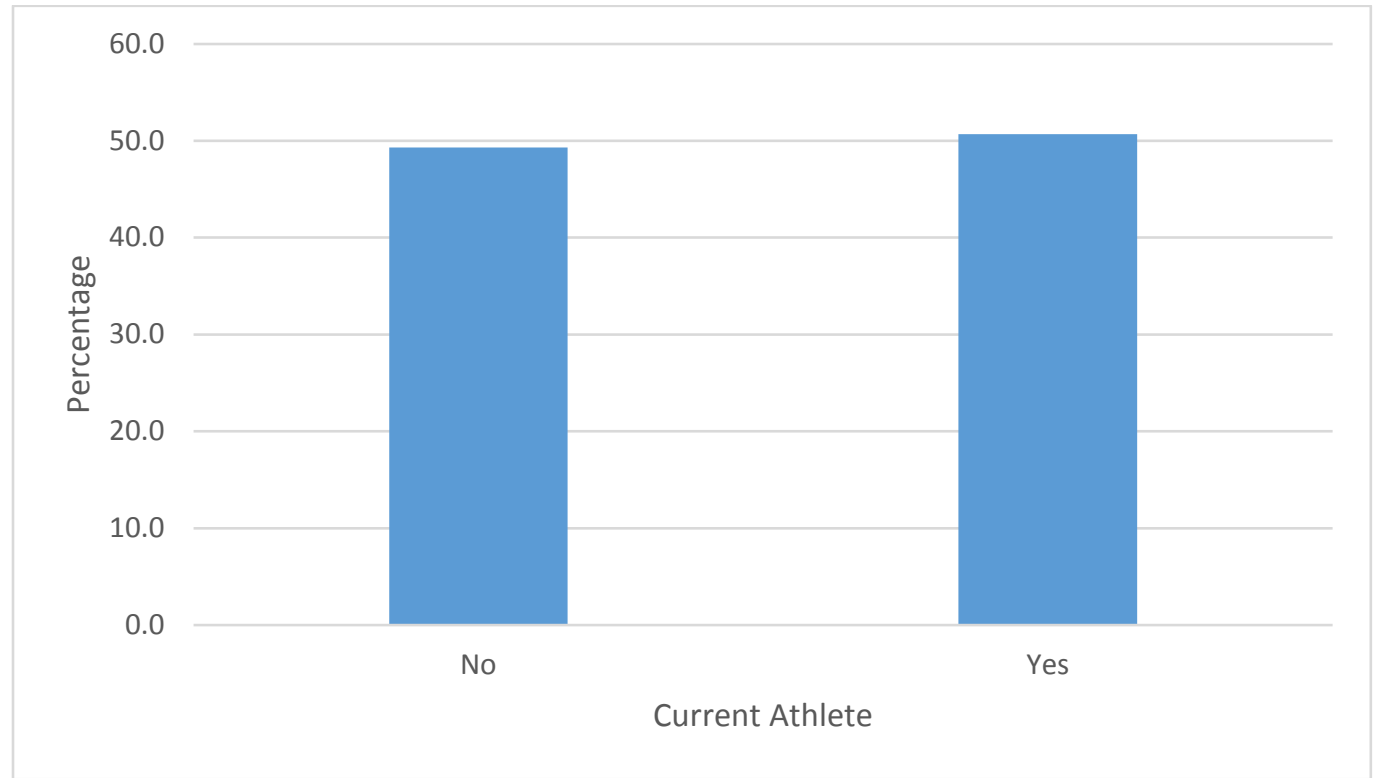

Figure 1. Current Athlete

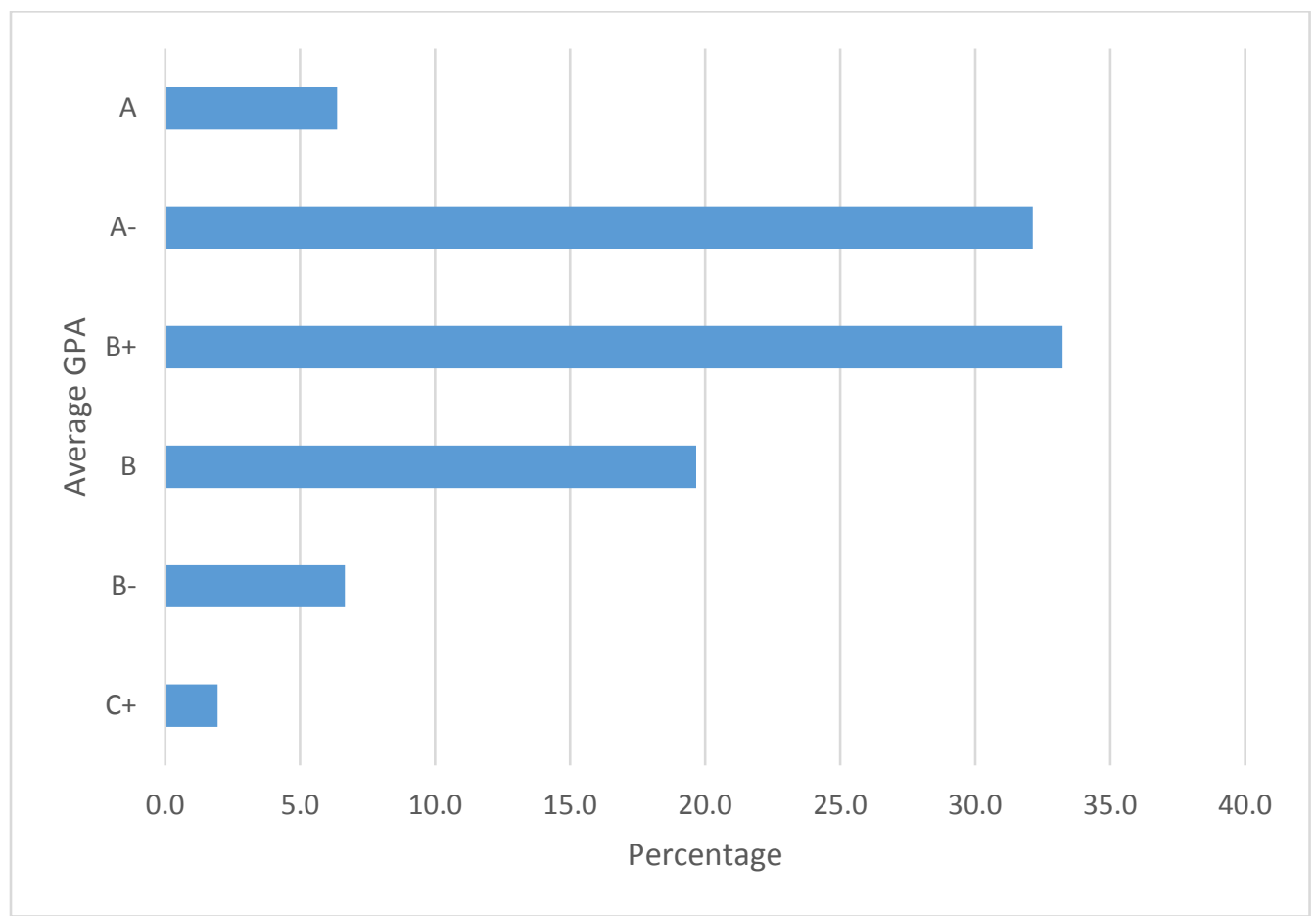

Figure 2. Average GPA 
ACADEMIC SUCCESS, ATHLETE VERSUS NON-ATHLETE

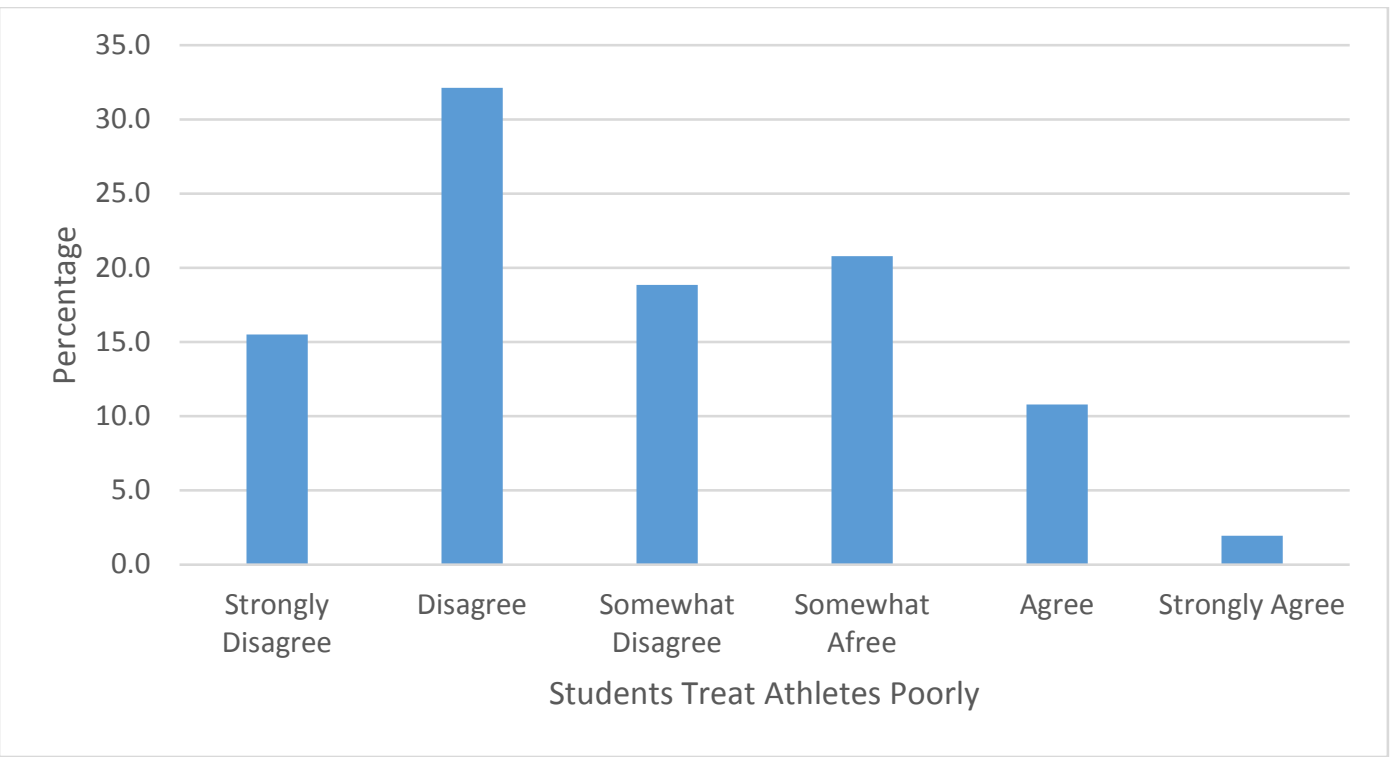

Figure 3. Agree that Students Treat Athletes Poorly

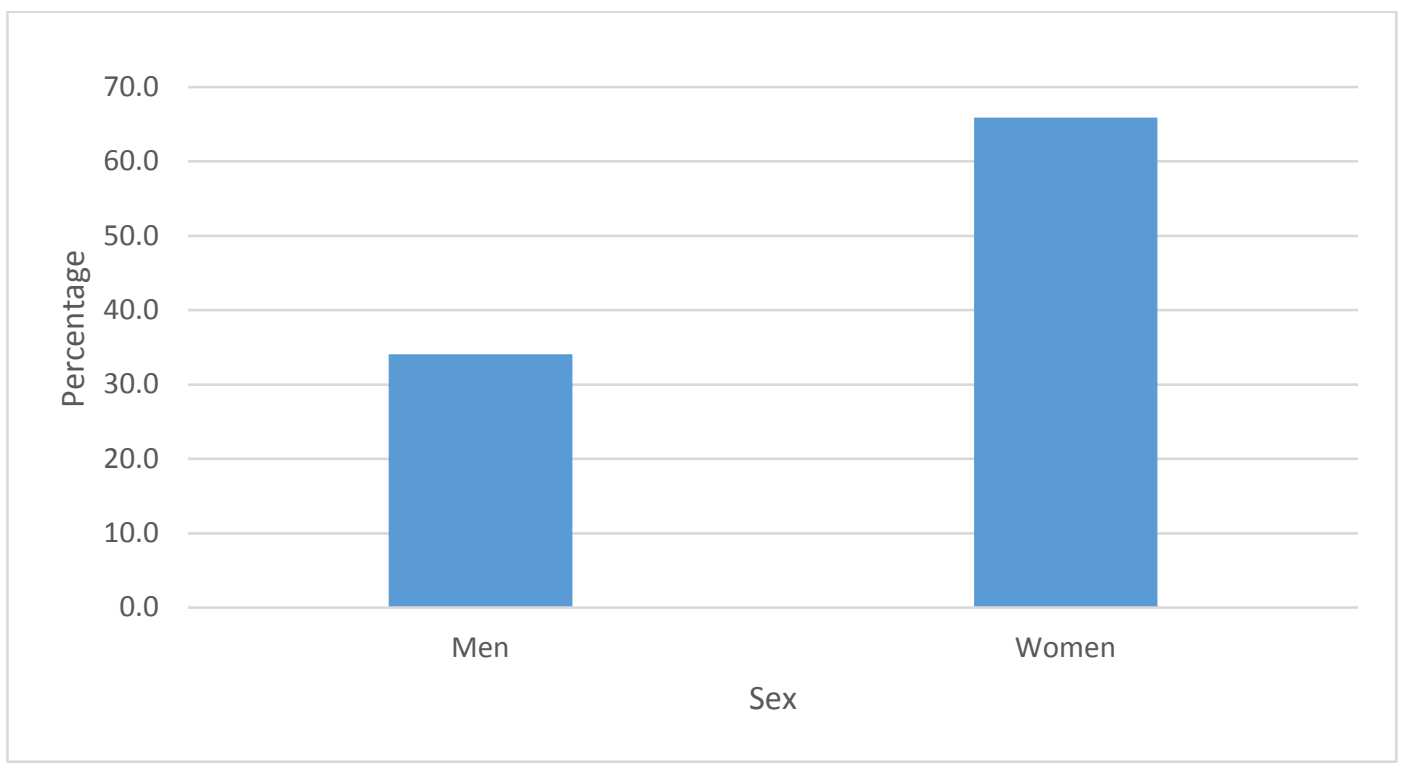

Figure 4. Sex 
ACADEMIC SUCCESS, ATHLETE VERSUS NON-ATHLETE

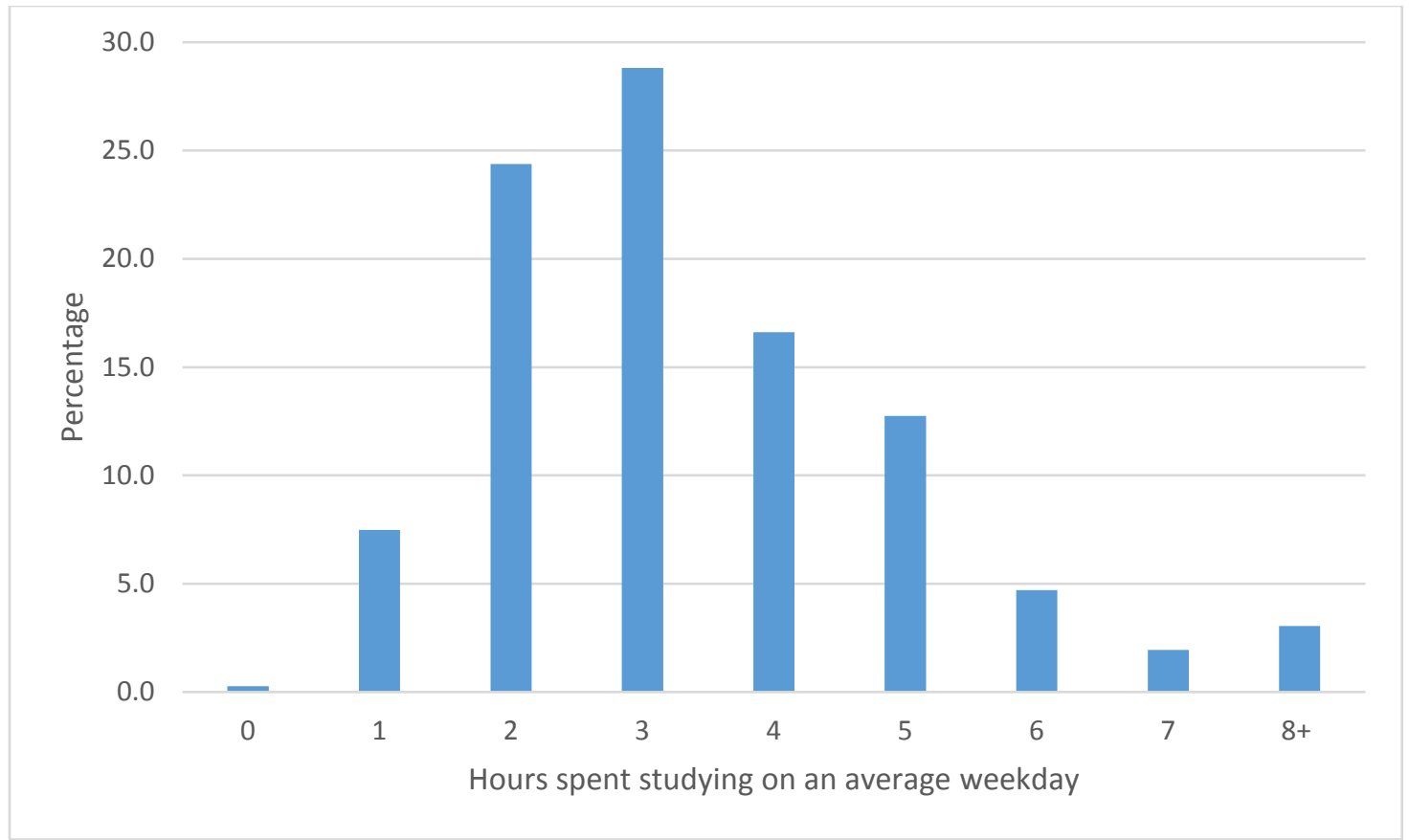

Figure 5. Hours Spent Studying on an Average Weekday

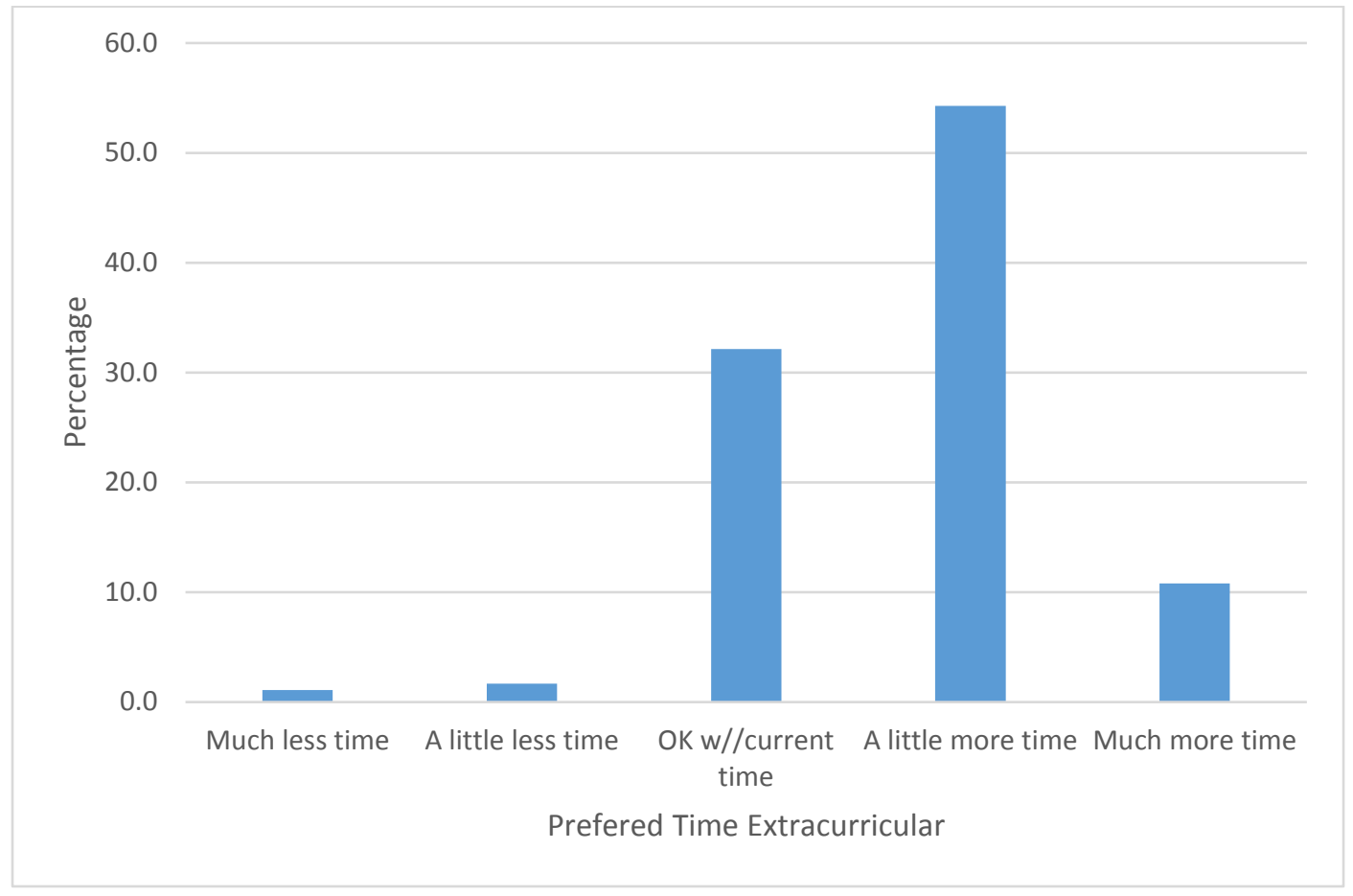

Figure 6. Prefer to Spend More Time on Extracurricular Activities 
Table 1. Mean, Median and Standard Deviation of all Variables $(N=361)$

\begin{tabular}{lcrr}
\hline Variable Names & Mean & Median & SD \\
\hline Current Athlete & .51 & 1.00 & .501 \\
GPA & 3.35 & 3.33 & .359 \\
Women & .66 & 1.00 & .475 \\
Poor Athlete Treatment & 2.85 & 3.00 & 1.319 \\
Preferred Extracurricular Time & 3.72 & 4.00 & .720 \\
Study Weekday Average & 3.39 & 3.00 & 1.611 \\
\hline
\end{tabular}

Table 2. Correlations ( $r$ ) Between GPA and Poor Athlete Treatment Among all Variables (Listwise Deletion, $N=361$ )

\begin{tabular}{|c|c|c|c|c|c|}
\hline & $\begin{array}{l}\text { Students treat } \\
\text { athletes poorly }\end{array}$ & Athlete & $\begin{array}{l}\text { Average study } \\
\text { time week day }\end{array}$ & $\begin{array}{l}\text { Time } \\
\text { Extracurricular }\end{array}$ & Women \\
\hline GPA & $-.195^{*}$ & $-.206^{*}$ & $.129^{*}$ & .061 & $.311^{*}$ \\
\hline $\begin{array}{l}\text { Students treat } \\
\text { athletes poorly }\end{array}$ & & -.007 & .046 & $-.111^{*}$ & $-.210^{*}$ \\
\hline Athlete & & & -.098 & -.099 & $-.113^{*}$ \\
\hline $\begin{array}{l}\text { Average study } \\
\text { time weekday }\end{array}$ & & & & .039 & .091 \\
\hline $\begin{array}{l}\text { Time extra } \\
\text { curricular }\end{array}$ & & & & & $.143^{*}$ \\
\hline
\end{tabular}

Table 3. Regression of GPA and students agree students treat athletes poorly on athletes, women, average study time weekday, and preferred time extracurricular

\begin{tabular}{lcc}
\hline Variable & GPA & $\begin{array}{r}\text { Students agree students treat } \\
\text { athletes poorly }\end{array}$ \\
\hline Athlete & $-.166^{*}$ & -.032 \\
Women & $.284^{*}$ & $-.207^{*}$ \\
Average study time weekday & .087 & .065 \\
Time extracurricular & .001 & -.088 \\
$R^{2}$ & .134 & .057 \\
$F(8,361)$ & $13.737^{*}$ & $5.341^{*}$ \\
${ }^{*} p<.05$ & &
\end{tabular}

